\title{
PENGEMBANGAN LEMBAR KERJA PESERTA DIDIK BERBASIS PROBLEM BASED LEARNING PADA MATERI FLUIDA STATIS
}

\author{
Muslem, M. Hasan, dan Rini Safitri \\ Universitas Syiah Kuala Banda Aceh \\ e-mail: ungohsabe89@gmail.com
}

\begin{abstract}
Abstrak
Penelitian ini bertujuan untuk mendeskripsikan tingkat kelayakan LKPD berbasis PBL pada materi fluida statis di MAN 2 Meulaboh. Penelitian ini merupakan penelitian pengembangan dengan jenis ADDIE. Pengumpulan data dilakukan melalui lembar validitas pakar konten, penyajian dan bahasa. Data penelitian yang didapatkan dianalisis secara deskriptif persentase. Hasil uji kelayakan LKPD oleh pakar konten mencapai $84,10 \%$, pakar penyajian mencapai $88,21 \%$, dan pakar bahasa mencapai $89,17 \%$. Berdasarkan hasil analisis data dapat disimpulkan bahwa pengembangan LKPD berbasis PBL layak diterapkan untuk jenjang SMA/MA.
\end{abstract}

Kata kunci: LKPD, PBL, Fluida Statis

\begin{abstract}
This study aims to describe the feasibility level of PBL-based LKPD on static fluid material in MAN 2 Meulaboh. This research is a research and development with ADDIE type. Data collection was obtained from the expert of content validity, presentation, and language. The research data obtained were analyzed by descriptive percentage. The results of the LKPD feasibility test by content experts reached $84.10 \%$, of presentation experts reached $88.21 \%$, and of language experts reached $89.17 \%$. Based on the results of data analysis, it can be concluded that the development of PBL-based LKPD is feasible to be applied in Senior High School.
\end{abstract}

Keywords: LKPD, PBL, Static Fluid

\section{PENDAHULUAN}

Fisika merupakan salah satu pelajaran pada tingkat SMA/MA yang wajib dipelajari oleh peserta didik jurusan IPA, yang mempelajari gelaja-gelaja dan fenomena alam. Menurut Yulianti dan Wiyanto (2009), bahwa inti dari pembelajaran fisika itu sendiri meliputi proses-proses sains yang dalam pembelajarannya memerlukan interaksi dengan obyek nyata serta interaksi dengan lingkungan belajarnya. Sehingga peserta didik selain mendapatkan pengetahuan dan menguasai konsep yang dipelajari juga meningkatnya motivasi dalam belajar, maka pembelajaran fisika menjadi hidup. Namun pada kenyataannya tidak demikian yang terjadi di MAN 2 Meulaboh, pembelajaran yang semestinya didominasi oleh peserta didik (student center) tetapi masih didominasi oleh guru (teacher center). MAN 2 Meulaboh merupakan sebuah madrasah yang memiliki lokasi strategis, dekat dengan kota dan mudah dijangkau oleh masyarakat. Kendatipun demikian, 
peserta didik MAN 2 Meulaboh memiliki karakter yang berbeda dengan madrasah/sekolah di pusat kota, dimana terlihat mereka masih acuh dan belum terbiasa untuk menggali informasi sendiri dari buku di perpustakaan dan internet.

Materi fisika mempunyai ciri yang sangat menonjol, yaitu pada konsep-konsep yang saling berkaitan artinya untuk dapat menguasai suatu konsep baru atau tertentu, peserta didik harus sudah memahami konsep-konsep lain yang terkait langsung atau tidak langsung dengan konsep yang sedang dipelajarinya. Hal ini sering dijumpai keluhan peserta didik mengenai pelajaran fisika. Para peserta didik selalu beranggapan bahwa fisika itu sulit dan menakutkan. Selain dari peserta didik sendiri, guru juga dalam penyampaian materi kurang dapat dipahami oleh peserta didik. Kondisi ini dikarenakan pembelajaran fisika yang masih menerapkan model pembelajaran yang tidak sesuai dengan konsep, belum mengkaitkan konsep dengan pengalaman peserta didik sehingga rendahnya motivasi belajar peserta didik.

Permasalahan tersebut mendadasari perlunya perubahan dan inovasi dalam pembelajaran, salah satunya adalah dengan penerapan media yang tepat. Salah satu media pembelajaran untuk mengaktifkan peserta didik dalam kelas adalah dengan lembar kerja peserta didik (LKPD). Menurut Prastowo (2012), LKPD merupakan suatu bahan ajar cetak berupa lembar-lembar kertas yang berisi materi, ringkasan, dan petunjuk-petunjuk pelaksanaan tugas pembelajaran yang harus dikerjakan oleh peserta didik, yang mengacu pada kompetensi dasar yang harus dicapai. Peserta didik mendapatkan pengetahuan dan pemahaman terhadap konsep yang dipelajarinya dengan melakukan kegiatan sesuai petunjuk LKPD, bukan dari penjelasan guru.

Jenis LKPD yang sering dijumpai selama ini hanya penyelesaian soal-soal, dan banyak terdapat yang tidak sesuai dengan karakter dan lingkungan peserta didik, sehingga peserta didik tidak ada motivasi dalam belajar yang berakibat pada rendahnya pemahaman konsep fisika, oleh karena itu perlu dikembangkannya LKPD yang sesuai dengan menginovasikan dengan model pembelajaran. Tujuan menginovasikan LKPD dengan model agar dalam pembelajaran lebih menarik dan peserta didik pun meningkat motivasi belajar sehingga peserta didik mampu menguasai konsep.

Pembelajaran selama ini (2019) masih berbasis guru, dan belum terjadi dua arah. Guru masih sebagai pusat pembelajaran (teacher center), sehingga peserta didik kurang terlibat dan tidak memahami materi yang disampaikan guru. Hal ini terjadi karena harus mengejar materi agar tuntas ketika menjelang ujian akhir sekolah (UAS). Padahal fisika merupakan pengetahuan dasar yang sangat diperlukan oleh peserta didik untuk menunjang ke tingkat pendidikan selanjutnya. Pembelajaran dengan LKPD yang disertai medel problem based learning (PBL) memberi kesempatan kepada peserta didik untuk lebih mengeksplorasikan berdasarkan kemampuannya sehingga tercipta belajar lebih 
mandiri dan hal ini akan mengubah orientasi belajar yang semula berpusat pada guru, kemudian berubah menjadi berpusat pada kegiatan peserta didik sendiri.

Menurut Atasoy dalam Celikler (2010), LKPD sebagai alat pokok yang terdiri dari langkah dan proses yang dibutuhkan oleh peserta didik dan membantu peserta didik untuk membentuk ilmu pengetahuan dan berpartisipasi penuh pada seluruh keiatan kelas dalam waktu yang sama. Penelitian Yasir, et al., (2013) pengembangan LKPD berbasis strategi belajar metakognitif untuk meningkatkan hasil belajar peserta didik, bahwa LKPD berbasis strategi belajar metakognitif memiliki batas layak secara teoritis dengan persentase $91 \%$ (kategori: sangat layak) dan secara empiris berdasarkan ketuntasan indikator hasil belajar 99,31\%. Widjajanti (2008), bahwa kualitas LKPD sangat mempengaruhi motivasi belajar peserta didik.

Berbagai penelitian pengembangan sudah dilakukan sebelumnya, bahwa LKPD berpengaruh terhadap kreativitas peserta didik. Penelitian Amalia, et al., (2014), bahwa LKPD berpengaruh terhadap kompetensi peserta didik. Penelitian Yildirim, et al., (2011), bahwa pembelajaran dengan menggunakan LKPD dapat meningkatkan prestasi belajar peserta didik. Hasil penelitian Pariska, et al., (2012), bahwa penerapan pembelajaran menggunakan LKPD berbasis PBL dapat mendorong peserta didik untuk berpikir kreatif. Penelitian Ozmen dan Yildirim (2005), hasil penelitian menunjukkan bahwa pembelajaran dengan menggunakan LKPD lebih efektif untuk meningkatkan hasil belajar peserta didik dibandingkan pembelajaran dengan model konvensional. Penelitian yang dilakukan oleh Indriani, et al., (2014) menyatakan bahwa pembelajaran dengan menggunakan LKPD dapat meningkatkan hasil belajar peserta didik.

Hal tersebut mendasari perlunya solusi atas kesulitan peserta didik pada materi fluida statis di MAN 2 Meulaboh, sehingga perlu dikembangkan LKPD berbasis PBL karena PBL merupakan salah satu model pembelajaran yang dapat digunakan untuk mengembangkan pola pikir peserta didik dan membuat peserta didik menjadi aktif. Sesuai dengan pendapat Nata (2011) pembelajaran pemecahan masalah ini merupakan kelanjutan dari pembelajaran pemahaman, pembelajaran diarahkan pada membantu peserta didik merestrukturisasi situasi yang dihadapinya agar dapat memecahkan masalah.

\section{METODE}

Penelitian ini merupakan penelitian pengembangan jenis ADDIE, yaitu pengembangan LKPD berbasis PBL pada materi fluida statis. Langkah-langkah penelitian dan pengembangan melalui model ADDIE (Sugiyono, 2006) adalah sebagai berikut :

Analisis, merupakan suatu proses mendefinisikan apa yang akan dipelajari oleh peserta didik. Maka untuk mengetahui atau menentukan apa yang harus dipelajari, kita 
harus melakukan beberapa kegiatan, diantaranya adalah (1) Melakukan analisis needs assessment (analisis kebutuhan) yaitu untuk menentukan kemampuan-kemampuan atau kompetensi yang perlu dipelajari oleh peserta didik, analisis yang dimaksud dalam penelitian ini merupakan analisis peningkatan pemahaman konsep dan motivasi belajar peserta didik yang dipengaruhi oleh penerapan LKPD berbasis PBL; (2) Melakukan analisis task analysis (analisis tugas) yaitu untuk mengetahui dan mengklarifikasi apakah masalah yang dihadapi memerlukan solusi berupa pembuatan perangkat pembelajaran. Oleh karena itu, output yang akan dihasilkan adalah berupa karakteristik atau profil calon peserta belajar, identifikasi kesenjangan, identifikasi kebutuhan dan analisis tugas yang rinci didasarkan atas kebutuhan. Desain, tahap ini dikenal juga dengan istilah membuat rancangan dengan merumuskan sebuah rancangan diantaranya (1) menentukan tujuan pembelajaran; (2) menyusun tes, dimana tes tersebut harus didasarkan pada tujuan pembelajaran yag telah dirumuskan; (3) menentukan strategi pembelajaran yang tepat dengan menggunakan metode diskusi untuk mencapai tujuan tersebut; (4) membuat LKPD berbasis PBL.

Pengembangan, merupakan proses mewujudkan desain menjadi kenyataan maka dilakukan pengembangan LKPD berbasis PBL. Satu langkah penting dalam tahap pengembangan adalah uji coba sebelum diimplementasikan uji coba kelas terbatas (kelas kecil). Tahap uji coba ini memang merupakan bagian dari salah satu langkah ADDIE yaitu evaluasi. Lebih tepatnya evaluasi formatif, karena hasilnya digunakan untuk memperbaiki sistem pembelajaran yang sedang kita kembangkan. Implementasi, merupakan langkah nyata untuk menerapkan LKPD berbasis PBL. Pada tahap ini LKPD berbasis PBL yang telah dikembangkan disusun sedemikian rupa sesuai dengan peran atau fungsinya agar bisa diimplementasikan sesuai desain awal. Implementasi yang dimaksud dalam penelitian ini adalah melakukan uji coba skala terbatas di kelas dan bahkan menerapkannya dalam pembelajaran dengan tujuan untuk meningkatkan pemahaman konsep peserta didik.

Evaluasi, tahap ini merupakan proses untuk melihat apakah LKPD berbasis PBL yang sedang dikembangkan berhasil atau tidak dan apakah sesuai dengan harapan awal atau tidak. Evaluasi yang terjadi pada setiap empat tahap di atas disebut evaluasi formatif, karena tujuannya untuk kebutuhan revisi. Misal, pada tahap rancangan, mungkin kita memerlukan salah satu bentuk evaluasi formatif misalnya revisi ahli untuk memberikan input terhadap rancangan yang sedang kita buat. Pada tahap pengembangan, mungkin perlu uji coba dari produk yang kita kembangkan atau mungkin perlu evaluasi kelompok kecil dan lain-lain.

Alur penelitian dan pengembangan melalui model ADDIE ditunjukkan pada Gambar 1. 


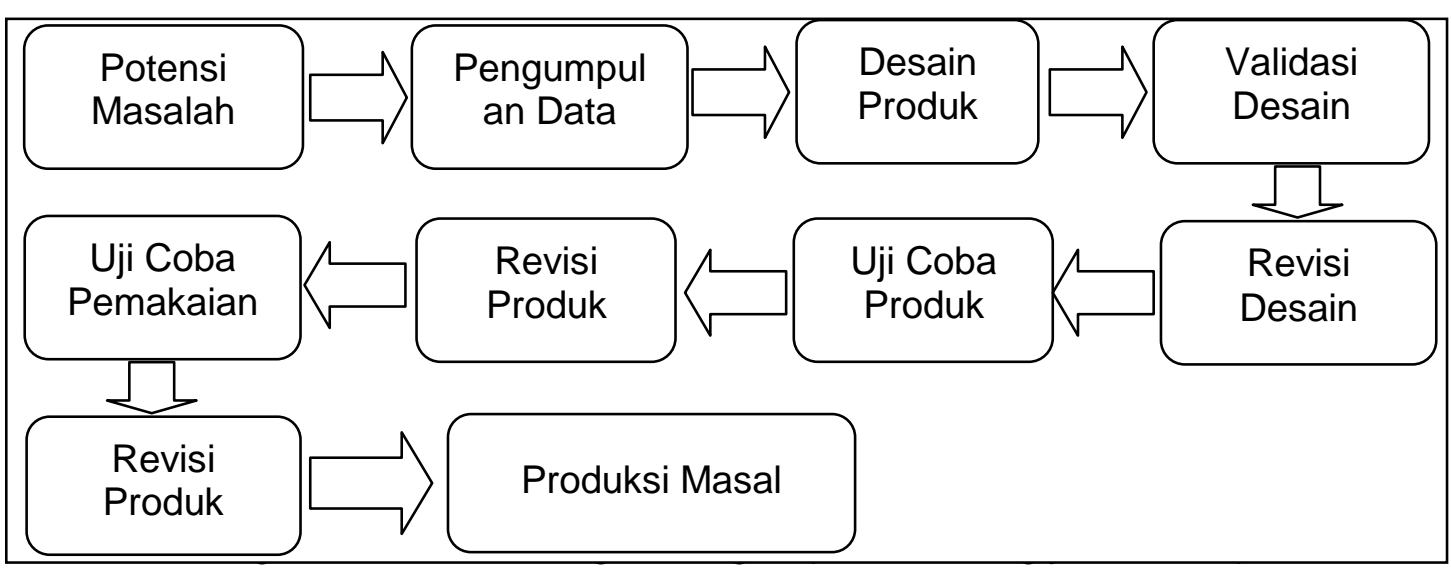

Gambar 1. Model Pengembangan ADDIE

\section{HASIL DAN PEMBAHASAN}

Validasi tahap I diperoleh jawaban 100\% positif untuk semua butir penilaian dari seluruh pakar. Berdasarkan hasil tersebut dapat dikatakan bahwa LKPD yang telah dikembangkan dinyatakan lolos validasi tahap I dan dinilai kembali pada validasi tahap II. Validasi tahap II dapat dilakukan dengan syarat pada validasi tahap I persentase yang didapatkan $100 \%$ atau semua pakar memberikan penilaian positif. Rekapitulasi hasil penilaian pakar tahap I terhadap modul dapat dilihat pada Tabel 1.

Tabel 1 Rekapitulasi Data Hasil Validasi Tahap I oleh Pakar terhadap LKPD

\begin{tabular}{ccccc}
\hline No & \multicolumn{1}{c}{ Validasi } & \multicolumn{2}{c}{ Persentase Penilaian ke } & Kriteria \\
\hline 1. & Pakar Isi (Konten) & $\mathbf{1}$ & $\mathbf{2}$ & Lolos \\
2. & Pakar Struktur & 100 & - & Lolos \\
3. & Pakar Bahasa & 79 & - & Lolos \\
\hline
\end{tabular}

LKPD yang telah lolos tahap I dinilai kembali secara lebih mendalam pada validasi tahap II yang dilakukan 2 kali yaitu sebelum uji coba skala terbatas dan sebelum uji coba skala luas. Berdasarkan hasil validasi sebelum uji coba skala terbatas dapat diketahui bahwa LKPD yang dikembangkan menunjukan hasil validasi pakar Isi (Konten) sebesar $71,48 \%$ termasuk dalam kriteria "layak", pakar struktur menunjukan hasil 83,75\% termasuk dalam kriteria "sangat layak" dan pakar bahasa menunjukan hasil 84,03\% termasuk dalam kriteria "sangat layak".

Hasil tersebut menunjukkan bahwa LKPD fluida statis yang telah dikembangkan dinyatakan layak dan dapat diuji pada uji coba skala terbatas. Rekapitulasi data hasil validasi pakar tahap II terhadap LKPD dapat dilihat pada Tabel 2.

Tabel 2. Rekapitulasi Data Hasil Validasi Tahap II oleh Pakar terhadap LKPD

\begin{tabular}{|c|c|c|c|c|}
\hline No & Validasi & \multicolumn{2}{|c|}{ Pesentase } & \multirow{2}{*}{ Kriteria } \\
\hline 1 & Pakar Isi (Konten) & $\begin{array}{c}\text { Tahap I } \\
7148\end{array}$ & Tahap II & \\
\hline 2 & Pakar Struktur & 83,75 & - & Sangat Lavak \\
\hline 3. & Pakar Bahasa & 62,50 & 84,03 & Sangat Layak \\
\hline
\end{tabular}


Setelah uji coba skala terbatas dilakukan, dilakukan validasi kembali sebelum dilakukan uji coba skala luas diketahui bahwa LKPD yang dikembangkan menunjukan hasil positif validasi pakar isi (konten) sebesar 85,09 dan 95,74 termasuk dalam kriteria "sangat layak" pakar struktur menunjukan hasil 84,03 dan 96,53 termasuk dalam kriteria "sangat layak" dan pakar bahasa menunjukan hasil 94,58 termasuk dalam kriteria "sangat layak". Rekapitulasi data hasil validasi pakar sebelum uji coba skala luas terhadap LKPD dapat dilihat pada Tabel 3.

Tabel 3. Rekapitulasi Data Hasil Validasi Tahap II oleh Pakar terhadap LKPD sebelum
\begin{tabular}{ccccc}
\multicolumn{5}{c}{ Uji Coba Skala Luas } \\
\cline { 3 - 5 } No & Validasi & Persentase & Kriteria \\
\hline 1. & Pakar Isi (Konten) & 85,09 & 95,74 & Sangat Layak \\
2. & Pakar Struktur & 84,03 & 96,58 & Sangat Layak \\
3. & Pakar Bahasa & 94,58 & - & Sangat Layak \\
\hline
\end{tabular}

Selama proses validasi saran dan komentar diberikan oleh pakar. Adapun beberapa perbaikan LKPD yang telah dilakukan adalah tersaji pada Tabel 4.

Tabel 4. Hasil Evaluasi dan Revisi LKPD

\begin{tabular}{|c|c|c|}
\hline No & Saran/Komentar & Perbaikan \\
\hline 1. & $\begin{array}{l}\text { Gambar perlu diperjelas lagi } \\
\text { dan berdasarkan fakta di } \\
\text { lapangan sesuai dengan } \\
\text { daerah Aceh. }\end{array}$ & $\begin{array}{l}\text { Meninjau gambar pada LKPD yang perlu } \\
\text { dilakukan perbaikan, memperjelas gambar, dan } \\
\text { menambahkan gambar yang sesuai dengan } \\
\text { dilingkungan sekitar Aceh. }\end{array}$ \\
\hline 2. & $\begin{array}{l}\text { Tampilan gambar } \\
\text { berwarna dan besar }\end{array}$ & $\begin{array}{l}\text { Meninjau kembali gambar-gambar dan } \\
\text { menggantikannya dengan gambar yang berwarna } \\
\text { dan besar agar lebih jelas }\end{array}$ \\
\hline 3. & $\begin{array}{l}\text { Tata tulisan yang belum sesuai } \\
\text { dengan EYD }\end{array}$ & $\begin{array}{l}\text { kembali dan memperbaiki tulisan yang } \\
\text { aku dan belum sesuai dengan EYD, } \\
\text { erpedoman pada kamus kamus bahasa }\end{array}$ \\
\hline 4. & $\begin{array}{l}\text { Mengkombinasikan warna dan } \\
\text { tulisan dengan baik agar } \\
\text { sedap dipandang mata. }\end{array}$ & $\begin{array}{l}\text { Meninjau kembali warna-warna pada LKPD dan } \\
\text { mengkonsultasikan dengan pakar agar tercipta } \\
\text { kombinasi warna yang baik. }\end{array}$ \\
\hline 5. & Literature terbaru & $\begin{array}{l}\text { Mencari dan menambahkan literature yang } \\
\text { terbaru. }\end{array}$ \\
\hline 6. & $\begin{array}{l}\text { Cek kembali langkah LKPD } \\
\text { dan kesesuaian dengan } \\
\text { langkah model PBL }\end{array}$ & $\begin{array}{l}\text { kkan pengecekan terhadap langkah LPKD } \\
\text { enyesuaikan dengan langkah model PBL. }\end{array}$ \\
\hline 7. & $\begin{array}{l}\text { Materi perlu ditambah dan } \\
\text { contoh soal. }\end{array}$ & ateri fluida statis beserta contoh \\
\hline 8. & kontekstual & $\begin{array}{l}\text { Melakukan revisi terhadap kasus materi fluida } \\
\text { statis yang kontekstual. }\end{array}$ \\
\hline
\end{tabular}

\section{SIMPULAN}

LKPD berbasis PBL yang dikembangkan layak digunakan untuk pembelajaran fisika pada jenjang SMA/MA. 


\section{DAFTAR PUSTAKA}

Amalia, Y.D., Asrizal dan Zulhendri K. 2014. Pengaruh Penerapan LKPD Beorientasi Pembelajaran Berbasis Masalah Terhadap Kompetensi Peserta didik kelas $X$ SMA N 1 Gunung Talang. Pillar of Phiysics Education, (2),17-24.

Celikler, D. 2010. The Effect of Worksheets Developed for the Subject of Chemical Compounds on Student Achievement and Permanent Learning. The International Journal of Research in Teacher Education, 1(1):42-51

Indriani, W., Murtiani, \& Gusnaedi. 2014. Pengaruh Penerapan LKPD Berbasis Strategi Pembelajaran Peningkatan Kemampuan Berpikir (SPPKB) terhadap Keterampilan Berpikir kreatif Peserta didik. Pillar of Physics Education. 2: 145-152.

Nata, A. 2011. Perspektif Islam Tentang Strategi Pembelajaran, Jakarta: Kencana Prenada Media Group

Ozmen, H., \& N. Yidirim. 2005. Effect of Work Sheet on Student's Success: Acids and Based Sample. Jurnal of Turkish Science Education 2(2): 10-13. Tersedia di http://www.tused.org/internet/tused/tusedv2i2s4 [diakses 26-6-2015]

Pariska, I. S., S. Elniati, \& Syafriandi. 2012. Pengembangan Lembar Kerja Peserta didik Berbasis Masalah. Jurnal Pendidikan Matematika, 1(1): 75-80.

Prastowo, A. 2012. Panduan Kreatif Membuat Bahan Ajar Inovatif. Yogjakarta: Diva Press.

Salirawati, D. 2004. Penyusunan dan Kegunaan LKPD dalam Proses Pembelajaran. Diakses dari http://staff.uny.ac.id/sites/default/files/pengabdian/das-salirawati-msidr/19penyusunnan-dan-kegunaan-LKPD.pdf pada tanggal 14 Juni 2015.

Sugiyono. 2006. Metode Penelitian Kuantitatif Kualitatif dan R \& D. Bandung: Alfabeta

Widjajanti, E. 2008. Kualitas Lembar Kerja Peserta didik. Makalah disampaikan dalam Kegiatan Pengabdian pada Masyarakat, FMIPA UNY, 22 Agustus 2008. Online. Tersedia di http://staff.uny.ac.id/system/files/pengabdian/endang-widjajanti-Ifx-msdr/kualitas-LKPD.pdf [diakses tanggal 15 Desember 2014]

Yasir, M. Endang S., dan Isnawati. 2013. Pengembangan Lembar Kerja Peserta didik (LKPD) Berbasis Strategi Belajar Metakognitif untuk Meningkatkan Hasil Belajar Peserta didik Pada Materi Pewarisan Sifat Manusia. Universitas Negeri Surabaya. Jurnal Online Bio Edu, 2(1):1-13.

Yildirim, N., K. Sevil, \& A. Alipasa. 2011. The Effect of The Worksheet on Students' Achievement In Chemical Equilibrum. Journal of Turkish Science Education 8(3):44.

Yulianti , D dan Wiyanto. 2009. Perancangan Pembelajaran Inovatif. Semarang: LP2M Universitas Negeri Semarang. 